\title{
RETOMANDO O DEBATE SOBRE O TRABALHO VOLANTE NA AGRICULTURA PAULISTA DOS ANOS 1980
}

José Giacomo Baccarin*

Resumo: No início dos anos 1980 a sociedade se deu conta da existência de milhares de trabalhadores rurais volantes ou boias-frias, empregados em condições precárias nos canaviais do Estado de São Paulo, o mais rico do Brasil. Chamaram a atenção as amplas greves e revoltas ocorridas em 1984, aparentemente sem organização prévia e lideranças definidas, assumindo caráter de explosão social. Estudos e atividades acadêmicas vinham tratando do tema trabalho temporário na agricultura brasileira desde os anos 1960, mais fortemente entre 1973 e 1983. Atualmente, esse tema recebe pouco destaque entre pesquisadores. O objetivo do artigo é recuperar o debate acadêmico ocorrido entre 1970 e 1980 no Brasil, discutindo especialmente as causas do surgimento dos volantes e algumas de suas características, em particular as relativas à eventualidade ou sazonalidade de sua ocupação.

Palavras-chave: Trabalhador volante. Relações de trabalho. Modernização agrícola.

\begin{abstract}
In the early 1980s Brazilian society became aware of the existence of thousands of rural temporary workers, employed in precarious conditions in sugarcane plantations in São Paulo state, the richest of Brazil. What drew attention were the large strikes and riots occurred in 1984, apparently without defined organization and leadership, assuming character of social explosion. Studies and academic activities had been working on the issue of temporary work in Brazilian agriculture since the 1960s, more strongly between 1973 and 1983. Currently, this issue receives little attention among researchers. The paper aims to regain academic debate occurred between 1970 and 1980 in Brazil, discussing especially the causes of the rise of the temporary workers and some of its characteristics, in particular those relating to the incidental or seasonal nature of their occupation.
\end{abstract}

Key Words: Temporary worker. Labor relations. Agricultural modernization.

\footnotetext{
* Professor e orientador do Programa de Pós-Graduação em Geografia do Instituto de Geociências e Ciências Exatas da UNESP, campus de Rio Claro. E-mail: baccarin@,fcav.unesp.br.
} 


\section{INTRODUÇÃO}

Eis que, no início dos anos 1980, a sociedade brasileira se deu conta da dura realidade de milhares de trabalhadores rurais, os chamados boias-frias ou volantes, em uma das mais prósperas regiões agrícolas brasileiras, a de Ribeirão Preto (SP), então marcada, entre outras atividades, por extensos canaviais e laranjais. Esses trabalhadores eram vistos, até certo ponto de forma simplificadora, como despossuídos da propriedade e da posse da terra, de direitos trabalhistas básicos, de condições mínimas de vida e, até mesmo, de trabalhos sistemáticos e continuados, não sendo possível, sequer, definir quem era seu patrão por um período de tempo superior a alguns meses.

A ampla visibilidade social dos volantes decorreu de movimentos grevistas e revoltas sociais ocorridas no início da safra de cana-de-açúcar, em maio 1984, que, a partir da pequena cidade de Guariba (SP), à época com menos de 30.000 habitantes (IBGE, 2015) e a menos de $50 \mathrm{~km}$ da cidade de Ribeirão Preto (SP), se estendeu para muitos outros municípios canavieiros paulistas. Concomitantemente, observaram-se movimentos reivindicatórios e grevistas na região com predominância de plantações de laranja e outros citros, destacando-se, nesse caso, o ocorrido na cidade de Bebedouro (SP), também próxima a Ribeirão Preto (BACCARIN, 1985).

Como uma das causas imediatas da chamada Revolta de Guariba foi apontada a mudança ocorrida em 1983, e que deveria ter continuidade em 1984, no sistema de corte manual de cana-de-açúcar, de cinco para sete ruas ou linhas. Embora trouxesse vantagens, em termos de produtividade agrícola e industrial, para os empresários rurais, o novo sistema aumentava a largura do eito de trabalho de seis para nove metros (supondo-se um espaçamento entre linhas de 1,5m), exigindo esforços adicionais para se depositar a cana cortada na rua central e dificultando a manutenção dos ganhos salariais obtidos nas cinco ruas (BACCARIN, 1984).
Contudo, havia questões de ordem mais geral que implicavam condições de vida precárias dos trabalhadores rurais. A economia brasileira, no início dos anos 1980, mostrava-se praticamente estagnada, o desemprego crescia e a inflação tendia a atingir $200 \%$ ao ano. Para muito dos volantes, agregava-se a instabilidade e a diminuição sazonal de oportunidades de emprego, mais pronunciada no período de entressafra da cana e da laranja, entre outubro/novembro de um ano e abril/maio do ano seguinte, comprometendo sua renda familiar.

Ao se iniciar a safra de 1984, esse conjunto de situações desencadeou a Revolta de Guariba, não precedida, ao que tudo indica, de uma organização prévia por parte de instituições formais ligadas aos volantes, especialmente sindicatos de trabalhadores rurais. Graziano da Silva (1997) afirma que alguns sindicatos da FETAESP (Federação dos Trabalhadores Rurais do Estado de São Paulo) vinham, desde 1983, formulando uma pauta específica para os canavieiros, incorporando questões como a forma de pagamento da cana cortada (por peso ou metro) e a eliminação das sete ruas. Contudo, o acontecido em Guariba, como salienta o autor, não teve relação com essa preparação sindical.

O descontentamento com as condições de vida se expressou em saque de um supermercado e na depredação das instalações da SABESP (Companhia de Saneamento Básico do Estado de São Paulo) de Guariba, cujas tarifas de água e esgoto se mostravam superiores à capacidade de pagamento dos volantes. Ao mesmo tempo, os trabalhadores se mobilizaram e em poucos dias todos os caminhões de turma foram impedidos de deixar a cidade para o trabalho no corte de cana-de-açúcar. Também rapidamente, outros municípios aderiram ao movimento, o que, de forma inédita, obrigou os patrões, com a intermediação do Governo do Estado de São Paulo, a aceitarem uma negociação de âmbito estadual e específica para as condições dos canavieiros. A sete ruas foi abolida, ocorreram ganhos salariais e melhoria em algumas 
58 BACCARIN. Retomando o debate sobre o trabalho volante na agricultura paulista dos anos 1980 condições de trabalho, embora uma importante reivindicação dos trabalhadores, a substituição do pagamento por tonelada pelo por metro de cana cortada, não tivesse sido aceita pelos patrões.

Além da intermediação da negociação, na ação pública destacou-se a forte violência policial empregada na repressão das manifestações populares e trabalhistas, com registro de muitos feridos e a morte de um morador de Guariba. As imagens do movimento, com os milhares de pessoas envolvidas, com cenas de brutalidade policial, em um momento em que o movimento de redemocratização do Brasil estava se fortalecendo, ganharam projeção na imprensa nacional e mesmo internacional, trazendo à tona uma situação social que, até então, além de seus próprios personagens, parecia ser objeto de preocupação de apenas um número pequeno de sindicalistas, de militantes sociais e de acadêmicos dedicados à questão agrária.

Na verdade, desde a década de 1960 vinham se difundindo, no meio acadêmico, estudos tratando da problemática do trabalho volante na agricultura, o que ganhou força entre 1975 e 1990. Nesse esforço, merece ser destacada a realização de seis Reuniões Nacionais sobre Mão-de-obra Volante na Agricultura, entre 1975 e 1980, sob a coordenação de integrantes do Departamento de Economia Rural da Faculdade de Ciências Agronômicas do campus de Botucatu UNESP (DEPARTAMENTO DE ECONOMIA RURAL FCA/UNESP, 1982). Alguns artigos e livros ganharam projeção, destacando-se análises feitas por Ângela Kageyama, José Graziano da Silva, José de Souza Martins, Maria Conceição D'Incao, Otávio Ianni e Vinícius Caldeira Brant, entre outros. Não exclusivamente, mas com predominância, o universo empírico considerado foi a estrutura social da agricultura paulista.

Uma das preocupações era discutir as causas da formação de um grande contingente de trabalhadores, que passaram a habitar o setor urbano, mas que,

na maior parte do tempo, continuavam dedicados às atividades agropecuárias. Questões mais gerais, de formação da estrutura agrária brasileira e das transformações capitalistas, foram consideradas, assim como temas mais específicos, como as características das mudanças tecnológicas em importantes lavouras do País e a implantação do Estatuto do Trabalhador Rural em 1963.

Entre as características dos volantes, mereceu discussão mais extensa a sazonalidade de sua ocupação ao longo do ano, associada às flutuações da demanda de força de trabalho agropecuária, levando alguns a adjetivarem seu trabalho como eventual. Um desdobramento de tal situação relacionava-se com a determinação do vínculo empregatício e o reconhecimento ou não dos direitos trabalhistas aos volantes. Era debatido se, com o passar do tempo, aumentaria ou não a precariedade e a instabilidade dos vínculos empregatícios dos boias-frias ou, de outra forma, se sua condição era transitória ou permanente. Nesse caso, a tendência seria a de crescer o contingente populacional com grande mobilidade entre as diversas atividades rurais e, mesmo, urbanas de curta duração, enquanto que, se transitória, o mercado de trabalho agropecuário desenvolveria, ao longo dos anos, vínculos mais regulares e duradouros. Nesse ponto, não se deve perder de vista uma questão de fundo, qual seja, para sua acumulação, o capital precisa que haja a mínima garantia de reprodução da força de trabalho e, sob o ponto de vista administrativo, muitas vezes, se exige maior organização e regularidade na arregimentação do trabalhador.

O objetivo do artigo é recuperar o debate acadêmico ocorrido nas décadas de 1970 e 1980 no Brasil, discutindo e, por vezes, reinterpretando, especialmente as causas do surgimento dos volantes na agricultura paulista e algumas de suas características, em particular as relativas à eventualidade ou sazonalidade de sua ocupação. Na segunda seção, o tema abordado é a formação da categoria volante. Na terceira, são discutidas suas condições de trabalho pre- 
dominantes no início dos anos 1980. Por fim, há uma seção de considerações finais.

Trabalhador VOlante - Desde SEMPre EXPropriado

Assume-se que a existência de centenas de milhares de trabalhadores volantes na agricultura paulista no início dos anos $1980^{1}$, em sua imensa maioria não detentores da propriedade ou da posse da terra, tinha, como causa básica, o que Martins (2010) define como o cativeiro da terra, ou o controle de grande parte das terras agrícolas por um pequeno número de proprietários rurais, que desde sempre caracterizou a estrutura fundiária brasileira, sob o amparo governamental.

$\mathrm{Na}$ gradativa passagem do regime de trabalho escravo para o de trabalho livre, a política oficial procurou dificultar, ao máximo, o acesso direto e relativamente autônomo à terra daqueles que poderiam (deveriam, na visão dos latifundiários) ser usados como força de trabalho nas grandes propriedades agropecuárias. Terras em abundância existiam no Brasil, ainda esparsamente povoado, no século XIX, mas a ação pública foi direcionada para que, em sua maior parte, ela fosse monopolizada por grandes proprietários fundiários.

Isso se evidenciou na aprovação da Lei $\mathrm{n}^{\circ}$. 601, conhecida como Lei de Terras, em 18 de setembro de 1850, mesmo ano (não por coincidência) em que se proibia oficialmente o tráfico negreiro. Sua aprovação só ocorreu após intensa discussão parlamentar, de 1842 a 1850, e com interregno de vinte e oito anos, desde a extinção da Lei de Sesmarias em 1822. Em seus dispositivos, a Lei de Terras acabou

${ }^{1}$ Kageyama (1982), com base nos dados do Censo Agropecuário, estima que o número de trabalhadores temporários correspondesse a $25 \%$ do total de ocupação na agricultura paulista em 1975. Graziano da Silva (1987), com base nos dados do IEA (Instituto de Economia Agrícola da Secretaria de Agricultura e Abastecimento do Governo do Estado de São Paulo), calcula em 320.070 os volantes no Estado de São Paulo em fevereiro de 1980 e 309.297 no mesmo mês de 1985 . por reconhecer o direito à propriedade dos detentores dos antigos títulos de sesmarias, bem como dos grandes posseiros, que, entre 1822 e 1850, conseguiram acesso a imensas áreas de terra (maiores que as das sesmarias, diga-se de passagem), bem como limitava o estabelecimento de novos proprietários, instituindo fortes penas para “[...] aqueles que após o registro das terras ocupassem o solo sem pagar por este [...]" (LINHARES; SILVA, 1981, p. 78)².

Ianni (1976) especifica mais os artigos da Lei de Terras que estabeleciam, por exemplo, que as terras devolutas só poderiam ser adquiridas, única e exclusivamente, pela compra e que o governo tinha o monopólio de sua venda, sendo parte da arrecadação daí decorrente destinada ao financiamento da vinda de colonos para trabalharem em estabelecimentos agrícolas. O autor ainda destaca, com base em uma citação de Varnhagen feita por Milliet $(1946)^{3}$, que os preços fixados nas vendas públicas tendiam a superar os registrados nas transações de terras particulares.

$\mathrm{Na}$ agricultura paulista, a escassez de trabalhadores, decorrente da proibição do tráfico internacional foi resolvida, em parte, com o comércio interno, registrando-se deslocamento de escravos do Nordeste, em decadência econômica, para os cafezais de São Paulo, em plena expansão. Com a Abolição, ganhou ainda maior importância o estímulo oficial, com recursos do Governo Central e da Província de São Paulo, à imigração de europeus, especialmente italianos, aportados no Brasil em grande número nas décadas finais do século XIX e iniciais do século XX. Como salienta Martins (2010, p. 117):

[...] esse processo é acompanhado pela implantação de uma política de imigração de trabalhadores estrangeiros, acentuada, sobretudo, a partir de 1880 ,

${ }^{2}$ Merece ser registrado, conforme citação de Linhares e Silva (1981, p. 78), trecho do discurso proferido, em 1843, pelo Ministro Joaquim Rodrigues Torres: "[...] queremos impedir que os trabalhadores que nos chegam de outras partes do mundo possam vir ao Brasil e em lugar de trabalhar para o proprietário pelo menos certo tempo [...] ocupem terras da Coroa imediatamente [...]".

${ }^{3}$ MILLIET, S. Roteiro do café. São Paulo: Bipa, 1946. 
dirigida principalmente para a região cafeeira de São Paulo. Entre 1887 e 1914, essa região recebeu 1.779.470 imigrantes, dos quais 845.816 eram italianos, seguindo-se em importância numérica os espanhóis e os portugueses.

A expectativa dos imigrantes era a de se transformarem em proprietários da terra, mas a realidade que a maior parte enfrentou foi a de serem alocados como empregados nas fazendas de café, sob uma forma de trabalho que ficou conhecida como colonato. A frustração daí derivada, aliás, fez que, mais adiante, o governo italiano estabelecesse repreensões diplomáticas ao governo brasileiro e que o número de imigrantes diminuísse sensivelmente, com os italianos se deslocando com mais intensidade para outros países, como Argentina e EUA.

O colonato encontra-se muito bem descrito na literatura histórica brasileira e convém levantar alguns de seus traços. Pressupunha uma relação de sujeição específica entre determinado fazendeiro de café e determinada família de colono. No caso dos imigrantes, tal relação começava a ser estabelecida na Hospedaria dos Imigrantes, local de estada provisória do imigrante e sua família e onde se dava sua arregimentação pelo cafeicultor. Até receber o pagamento em dinheiro após o primeiro ano de trabalho, o colono comprava gêneros de subsistência nos armazéns da propriedade rural, assumindo uma dívida que, no mais das vezes, se prorrogava pelos anos seguintes. Tal fato não impedia, mas dificultava o rompimento de contrato entre o colono e o cafeicultor.

De acordo com o tamanho de sua família, esse contrato previa que o colono assumisse o cuidado de alguns milhares de pés de café, realizando atividades como capina, arruamento, desbravamento e outras, sendo remunerado monetariamente por isso. Também recebia em dinheiro por serviços eventuais feitos em outras áreas da propriedade, em operações no terreiro de secagem do café e, especialmente, pela quantidade desse produto que a família colhia a cada ano.

Ao mesmo tempo, o colono tinha a permissão de cultivar gêneros de subsistência, arroz, feijão, milho e outros, próximo à sua residência, em áreas não ocupadas pelo cafezal ou mesmo no espaço entre as linhas dessa lavoura, enquanto o café tivesse pequeno porte. Aquela permissão se estendia para a criação de pequenos animais, como porcos e galinhas, e de algumas poucas vacas de leite, mantidas nos pastos da propriedade. Outro item importante era a cessão de moradia no interior da propriedade para o colono e sua família.

Há algumas quantificações desse pagamento misto. De acordo com Ettori, Gonzales e Bastos (1982), a remuneração do colono no café seria de $73 \%$ em dinheiro e 27\% em espécie. Martins (2010) estima participação maior dos gêneros de subsistência, próxima a $40 \%$ da remuneração total do colono.

Entende-se que essa remuneração mista não descaracterizava a relação entre patrão (capitalista) e empregado (proletário), mas estava relacionada com o nível de desenvolvimento que, à época, o capitalismo tinha em zonas pioneiras da agricultura paulista. Garantido o relativo monopólio da terra, era necessário suprir as debilidades então evidenciadas no mercado de trabalho e de gêneros de subsistência, que são explicitadas nos textos de Ianni (1976) e Brant (1977), por exemplo.

$\mathrm{Na}$ lavoura cafeeira, a necessidade de força de trabalho era muito mais intensa na época da colheita, que se estendia entre maio e agosto/setembro. A colheita em si era precedida pelo arruamento do cafezal e seguida pela secagem dos grãos ao sol nos terreirões, todas as três atividades necessitando de muitas pessoas. Ainda que se pudessem obter braços extras fora da propriedade, ao que tudo indica isso não se mostrava suficiente, dando-se preferência à manutenção dos trabalhadores necessários na colheita (pelo menos, em sua imensa maioria) como colonos na fa- 
zenda. Quando as atividades do café se mostravam menos exigentes em força de trabalho, em sua entressafra, os colonos se dedicavam também a atividades em outras lavouras, em grande parte para seu próprio sustento.

Esse arranjo diminuía a necessidade de pagamento monetário aos trabalhadores, posto que parte considerável de sua reprodução era garantida pela produção de gêneros de subsistência. A terra, escassa para o colono, era abundante para o cafeicultor e, enquanto seu preço se mostrasse baixo e não estimulasse seu uso comercial em toda a sua extensão, podia ser cedida parcialmente para produção de subsistência. Ao mesmo tempo, tal arranjo assegurava a produção local de gêneros de primeira necessidade, que poderiam faltar, dada a precariedade dos meios de transporte e a baixa integração dos mercados regionais agropecuários, com a evidente exceção do café.

É importante levar em conta também que a produção de gêneros alimentícios nas entrelinhas do café só podia acontecer posto que o espaçamento entre elas era elevado, em relação ao atualmente praticado, e suas capinas eram feitas manualmente, no máximo com uso de animais de trabalho, mas sem emprego de tratores. Graziano da Silva (1981) chega a dizer que, enquanto não se constituiu um mercado de trabalho urbano-rural, a mecanização dos tratos culturais no café foi limitada intencionalmente pelo proprietário, pois não se teria o que fazer com a força de trabalho disponível no estabelecimento em momentos em que não ocorresse a colheita do café.

Pode-se considerar a relação de trabalho do colonato, estabelecida entre o grande proprietário (cafeicultor, no mais das vezes) e colono, como a predominante na agricultura paulista, especialmente quanto à renda agropecuária obtida. Contudo, a estrutura social rural era bem mais complexa, existindo, além do fazendeiro (na linguagem corrente), sitiantes e chacareiros, ou seja, médios e pequenos agricultores, detentores autônomos da posse e, em muitos casos, da propriedade da terra.

Ainda que não se referindo ao período aqui analisado, mas sim ao colonial, Linhares e Silva (1981) falam da constituição de pequena produção em terras virgens, ao arrepio da lei, mas que não se conseguia reprimir, em decorrência da grande disponibilidade de terras devolutas no Brasil. Isso se deu nas franjas da lavoura canavieira no Nordeste brasileiro no período colonial ${ }^{4}$ e se pode supor que algo semelhante tenha ocorrido na expansão da lavoura cafeeira pelo interior paulista no Império e décadas iniciais da República.

D’Incao (1983), ao se referir à colonização da região da Alta Sorocabana, próxima a Presidente Prudente (SP), diferencia a apropriação da terra por fazendeiros, que controlavam vastas áreas usadas para exploração agropecuária, daquela realizada por comerciantes de terra (às vezes, ligados às companhias de estrada de ferro), que loteavam e permitiam o acesso à terra, mediante pagamento a prazo, por pequenos sitiantes. A partilha de propriedades rurais nas heranças e a compra de parcelas de grandes propriedades loteadas após crises cafeeiras, são outras formas descritas na literatura histórica, que possibilitaram o acesso à terra por pequenos agricultores.

Nas décadas de desagregação do colonato até o momento em que o trabalho volante se revelasse como relação de emprego predominante na agricultura paulista, de forma geral, não faltou suprimento adequado (sob o ponto de vista dos interesses patronais) de força de trabalho para as atividades agropecuárias do Estado.

Tal fato é muito bem descrito por Lopes

\footnotetext{
4 "Nas regiões de maior adensamento das fazendas de cana e demais produtos de exportação tornava-se impossível o surgimento de um campesinato livre face à grande pressão exercida pelos 'homens bons' sobre os mecanismos de distribuição de terras. Nada, porém, impedia que homens livres pobres ou negros fugidos fossem, aos poucos, se internando nos sertões e estabelecendo suas roças ao longo de rios ou caminhos, constituindo-se numa retaguarda da ocupação branca do litoral." (LINHARES; SILVA, 1981: p. 130).
} 
62 BACCARIN. Retomando o debate sobre o trabalho volante na agricultura paulista dos anos 1980

(1972), ao mostrar que, ao longo do século XX, os imigrantes foram sendo substituídos por migrantes, em especial os oriundos do Nordeste. Assim, no quinquênio 1901-05, das 205.297 pessoas que chegaram a São Paulo de outros lugares, 94,4\% eram imigrantes e apenas 5,6\% migrantes nacionais. Já entre 1956-60, os migrantes nacionais representaram $76,5 \%$ do total de 676.984 novas pessoas vindas para o Estado e registradas pelo Departamento de Imigração e Colonização da Secretaria da Agricultura do Estado de São Paulo 5 .

No mais das vezes, os migrantes nordestinos deixavam uma situação de "economia natural", marcada pela produção de subsistência, com baixo nível de monetização, para serem empregados em empresas paulistas. Embora crescesse, com o tempo, o direcionamento para empresas da indústria de transformação e de construção civil, Lopes (1972) informa que, em sua grande maioria, os novos contingentes populacionais se destinavam à agricultura, para o café inicialmente e, depois, também para o algodão. $\mathrm{O}$ apoio público continuava presente no aliciamento de migrantes, conforme essa citação: "O aliciamento, a concessão de passagens e o encaminhamento dos trabalhadores às fazendas, foram, entre outras as formas principais do Governo Paulista manifestar seu interesse em atender à fome de braços dos fazendeiros do Estado". (COSTA PINTO, 1952 apud LOPES, 1972, p. 59).

A ocupação de regiões pioneiras do território paulista estendeu-se até a década de 1930, quando terras de regiões mais a oeste acabaram por ser apropriadas, entre elas as do Pontal do Paranapanema, no Sudoeste de São Paulo. Ainda havia no interior das propriedades rurais, especialmente das grandes, reservas de terras com vegetação natural a serem ex-

\footnotetext{
${ }^{5}$ Além de chamar a atenção o fato de ser a Secretaria de Agricultura que tratava da migração, é bom destacar que o movimento migratório foi marcado por instabilidades, com registros de relativamente baixos números, como nos quinquênios 1916-20 e 1941-45, e de picos, como em 1926-30 e 1951-55, quando aportaram em São Paulo 973.586 migrantes e imigrantes (LOPES, 1972, p. 58).
}

ploradas por atividades agropecuárias. Isso deixou de ser possível entre as décadas de 1960 e 1970, quando as reservas naturais atingiram, praticamente, a mesma participação na área total dos estabelecimentos agropecuários paulistas, próxima a $10 \%$, que a constatada atualmente (GONÇALVES; CASTANHO FILHO, 2006).

A escassez relativa de terras agrícolas acabou por refletir em seus preços, que foram se elevando, e no seu uso econômico. Cada vez mais, tornava-se menos racional a cessão de áreas para produção de subsistência, muitas vezes com técnicas tradicionais e baixa produtividade, em comparação às alternativas de sua exploração voltada para o mercado, com o uso de tecnologias mecânicas e químico-biológicas, garantindo-se maior produção por área e, em princípio, maior capacidade de remunerar o ativo imobiliário agropecuário.

Outras transformações foram se processando na realidade paulista. $\mathrm{O}$ desenvolvimento dos meios de transporte, entre os quais o ferroviário, com grande importância inicial, e o rodoviário, que assumiu a supremacia após 1960, possibilitou maior integração dos mercados e circulação de mercadorias, tornando, paulatinamente, dispensável a produção local de gêneros agropecuários de primeira necessidade.

É interessante destacar que, após a crise cafeeira de 1930, a agricultura paulista entrou em uma fase de maior diversificação econômica, com crescimento dos mercados do algodão, milho e de produtos consumidos sem maiores transformações pela população, como leite, arroz e feijão. De atividades, em grande parte, subsidiárias ao café, esses produtos passaram a ser encarados como prioritários para exploração econômica por inúmeros estabelecimentos agropecuários.

A urbanização crescente, com diminuição relativa, em um primeiro momento, e absoluta, posteriormente, da população rural, é outra mudança a 
63 BACCARIN. Retomando o debate sobre o trabalho volante na agricultura paulista dos anos 1980 ser destacada. Cresceram as cidades, não absorvendo, total e permanentemente, todos os seus moradores em atividades industriais e de serviços. Muitos deles, em cidades menores constituindo-se parcela majoritária dos seus trabalhadores, continuaram a se dedicar às atividades agropecuárias. Gonzales e Bastos (1982), com base no Censo Demográfico, informam que 26,6\% dos trabalhadores agropecuários moravam nas cidades paulistas em 1970, porcentagem que, muito provavelmente, continuou aumentando nas décadas seguintes ${ }^{6}$.

Um aspecto a ser destacado desse fato é que, ainda que se acrescentassem o transporte e o agenciamento dos trabalhadores das cidades para a zona rural ao custo de produção agropecuário, isso era mais do que compensado pela isenção que os empregadores agrícolas obtinham quanto à reprodução da força de trabalho. Como destaca Saint (1980, p. 506):

Devido ao grande número de desempregados ex-rurais e às periódicas demandas elevadas de mão-de-obra, os proprietários rurais acharam economicamente mais vantajoso transportar trabalhadores diaristas das cidades para os estabelecimentos agrícolas, em vez de manter uma força de trabalho residente, com seus custos em termos de benefícios exigidos pela legislação trabalhista, terra para a produção de subsistência e pagamentos em espécie de vários tipos (por exemplo, lenha, gêneros alimentícios, habitação, etc.).

Além do mais, como morador da cidade, o trabalhador rural poderia ser mais facilmente arregimentado, muitas vezes com a intermediação de empreiteiros de mão-de-obra ("gatos", na denominação pejorativa), por diferentes agricultores, de acordo com suas necessidades sazonais de ocupação. Bem como poderia se dedicar, eventualmente, a atividades urbanas com pequenas exigências de qualificação

\footnotetext{
${ }^{6}$ Graziano da Silva (1982, p. 158), com base em dados do IEA, afirma que o porcentual de trabalhadores agrícolas não residentes nos estabelecimentos agropecuários de São Paulo passou de $16 \%$ para $36 \%$ entre 1964 e 1975.
}

profissional, na construção civil ou em serviços domésticos, por exemplo.

Até para aproveitar parte da citação de Saint, convém discutir o papel da legislação trabalhista, em específico a implantação do Estatuto do Trabalhador Rural (ETR), em 1963, na formação do trabalhador volante. Alguns, como Gonzales e Bastos (1982), partem da ideia de que o trabalhador rural permanente estaria protegido pelo ETR e, embora sua diária "a seco" pudesse ser menor que a do volante, não protegido pelo ETR, quando computados os encargos trabalhistas, o custo do primeiro se mostraria mais elevado que o do segundo ${ }^{7}$. Afirmam que o ETR só ampararia o trabalhador quando o contrato de trabalho, incluindo suas prorrogações, ultrapassasse um ano ininterrupto.

Diferentemente do considerado por Gonzales e Bastos (1982), até onde se consegue perceber das leituras dos artigos $6^{\circ}$. e $63^{\circ} .^{8}$ do ETR, o trabalho volante não estaria totalmente desamparado pela legislação, sendo-lhe assegurado o recebimento pelo menos do descanso semanal remunerado (Art. $42^{\circ}$. do ETR) e, talvez, de férias remuneradas proporcionais ao tempo de serviço, desde que este ultrapassasse 150 dias (Art. $43^{\circ}$. do ETR). Por sua vez, o Artigo $79^{\circ}$. do ETR explicitava claramente que a indenização por rescisão de contrato de trabalho seria obrigatória apenas no

${ }^{7}$ Para as condições vigentes em março de 1973 no Estado de São Paulo, os autores estimam que o custo da mão-de-obra permanente, diária mais encargos sociais, seria $10,2 \%$ mais alta que a do volante (GONZALES; BASTOS, 1982, p. 53). Ainda que não explícito no texto, pressupõe-se que os autores estejam considerando que na diária do volante estejam incluídos os gastos com transporte e a intermediação dos empreiteiros. Graziano da Silva (1982, p. 153) chega a diferenças ainda maiores para o ano de 1976 em uma simulação para a lavoura canavieira, calculando que o custo do volante seria de apenas de $58 \%$ do trabalhador permanente, ambos com os direitos trabalhistas assegurados.

8 "Art. $6^{\circ}$. Desde que o contrato de trabalho rural provisório, avulso ou volante ultrapasse um ano, incluídas as prorrogações, será o trabalhador considerado, permanente, para todos os efeitos desta lei.[...] Art. 63\%.. O contrato individual, de trabalho rural poderá ser oral ou escrito, Por Prazo determinado ou indeterminado, provando-se por qualquer meio permitido em direito e especialmente, pelas anotações constantes da Carteira Profissional do Trabalhador Rural, as quais não podem ser contestadas." (BRASIL, 2015) 
64 BACCARIN. Retomando o debate sobre o trabalho volante na agricultura paulista dos anos 1980 contrato de trabalho igual ou superior a um ano.

Já em 1973, a Lei ${ }^{\circ} .5 .889$, de 8 de junho de 1973, que revogou o ETR, garantiu em seu Art. $14^{\text {o }} .^{9}$ que o trabalhador temporário tivesse direito à indenização ao final do contrato de trabalho. Mas apenas a Lei ${ }^{\circ}$. 11.178, de 2008 (BRASIL, 2015b) deixou explícito que o trabalhador rural "por pequeno prazo" tinha assegurados todos os direitos trabalhistas, revelando a longa disputa jurídica e social em torno do tema.

Nesse interregno, não faltou empregador rural que usou a contratação de volantes como forma de tentar burlar a legislação trabalhista. Contudo, deve-se dizer que as decisões da Justiça do Trabalho há muitos anos, certamente desde o início da década de 1980 pelo menos, vêm garantindo direitos trabalhistas ao volante, não o considerando como exercendo trabalho eventual (esse ponto será retomado adiante).

Outra tentativa de burla à legislação trabalhista, citada por alguns autores, se dava por meio de contratos entre os grandes proprietários e pequenos parceiros ou arrendatários. D’Incao (1975) considera que isso, em grande parte das vezes, não passava de assalariamento disfarçado, citando um exemplo de um latifundiário da região do Pontal do Paranapanema (SP) que tinha contratos com algo próximo a 300 arrendatários. A autora afirma também que o trabalho volante ("assalariamento puro") vinha substituindo o assalariamento disfarçado dos parceiros e arrendatários.

Quanto às remunerações não monetárias, tanto o ETR quanto a Lei $\mathrm{n}^{\circ} .5 .889$ previam que o empregador poderia descontar do salário do trabalhador rural, em limite de até $20 \%$ do salário mínimo regional, a concessão do uso de moradia no estabelecimento agropecuário e, em limite de até $25 \%$ do salário míni-

9 “Art. 14. Expirado normalmente o contrato, a empresa pagará ao safrista, a título de indenização do tempo de serviço, importância correspondente a $1 / 12$ (um doze avos) do salário mensal, por mês de serviço ou fração superior a 14 (quatorze) dias." (BRASIL, 2015a)

A partir disso, deve se relativizar a citação anterior de Saint (1980) no que se refere aos custos arcados pelo empregador com moradia e gêneros alimentícios, em especial o muito comum fornecimento diário de leite de vaca in natura, julgando que a nova legislação, nesses aspectos, não confrontava totalmente o que se estabelecia no colonato.

Contudo, quanto à produção de subsistência pelo próprio trabalhador, salvo melhor interpretação, a nova legislação impunha-lhe fortes limites. Seu Art. $41^{\mathrm{o}} .^{10}$ (quase que ipsis litteris reproduzido pelo Art. $12^{\circ}$. da Lei 5.889 e em vigor até o presente momento) estabelecia que aquela produção não poderia compor o salário mínimo do trabalhador, mas a ele deveria ser acrescentada. Supondo-se que a remuneração do trabalhador rural tendia a ser estabelecida próxima à estipulada pelo salário mínimo, a nova legislação estimulava a substituição da parcela do pagamento em espécie obtida diretamente pelo trabalhador, nas atividades de subsistência, pelo pagamento monetário e, portanto, as limitava.

Ainda que se possa considerar que as mudanças na legislação tenham acelerado as transformações nas relações de trabalho, conforme o faz Graziano da Silva (1981), entende-se que suas causas mais fundamentais são outras e já vinham se explicitando anteriormente à implantação do ETR em 1963. Nesse sentido, Brant (1975) informa que na região de Assis (SP), na década de 1940, o número de trabalhadores permanentes nas propriedades rurais havia caído em número próximo a $25 \%$, enquanto o número de trabalhadores temporários crescia mais de 2,5 vezes.

O processo acelerou-se nas décadas se-

\footnotetext{
10 "Art. 41 . Nas regiões em que se adote a plantação subsidiária ou intercalar (cultura secundária), a cargo do trabalhador rural, quando autorizada ou permitida, será objeto de contrato em separado.

Parágrafo único. Embora podendo integrar o resultado anual a que tiver direito o trabalhador rural, a plantação subsidiária ou Intercalar não poderá compor a parte correspondente ao salário-mínimo, na remuneração geral do trabalhador, durante o ano agrícola." (BRASIL, 2015).
} 
guintes, até chegar à situação atual, em que a força de trabalho dos trabalhadores residentes nas empresas rurais é nitidamente secundária em relação às necessidades globais de força de trabalho, asseguradas principalmente pelo trabalho temporário e pela mecanização. (BRANT, 1975, p. 52).

Como já comentado, o esgotamento da fronteira e o aumento do preço da terra agrícola foram desestimulando os proprietários rurais a concederem seu uso para a produção de subsistência, procurando-se obter o máximo de rentabilidade possível por hectare explorado ${ }^{11}$. Também já se comentou que a urbanização e o crescimento populacional no estado de São Paulo garantiam maiores facilidades para se obter, em cidades próximas à propriedade rural, trabalhadores para a execução de atividades de duração não contínua, ao mesmo tempo que a maior integração dos mercados tornava dispensável a produção de gêneros de primeira necessidade localmente.

Uma parte dos colonos conseguiu se transformar em proprietário rural, destacando-se o acontecido após a crise cafeeira de 1930. Mas, ao que tudo indica, o movimento social predominante, no que se refere às relações de trabalho na agricultura, foi aquele que resultou na transformação do colono em trabalhador volante. E, pode-se acrescentar outra razão para esse fato, quais sejam as transformações tecnológicas na agricultura paulista, em especial sua mecanização, que ganhou celeridade a partir dos anos 1960, inclusive em decorrência de estímulos creditícios bancados

11 Não se está desprezando o fato de que uma parcela de proprietários rurais mantinha seus imóveis, preferencialmente, para fins de ganhos imobiliários e não agropecuários. Nesse caso, o mais comum é que se mantivesse a área ocupada com pastagem para exploração de pecuária extensiva, com muito baixa necessidade de força de trabalho e o mínimo de moradores possível. Graziano da Silva (1981) afirma que a propriedade rural com pequeno número de moradores permanentes era mais fácil de ser comercializada e alcançava valores mais altos. pela política federal de modernização da agricultura.

Graziano da Silva (1981) discute como a mecanização em culturas como algodão, café, cana-de-açúcar e laranja foi limitando o colonato e a manutenção de grandes contingentes de trabalhadores permanentes. Operações como o preparo de solo, tratos culturais, como capinas, e, até certo ponto, plantio, foram mais facilmente mecanizadas, diminuindo, muito intensamente, a necessidade de força de trabalho (o que no caso das capinas foi potencializado pelo emprego de herbicidas) e dificultando o cultivo de gêneros de subsistência nas entrelinhas do café e da laranja, por exemplo. Ao mesmo tempo, naquelas quatro culturas e em outras de menor importância, como o amendoim, a colheita, pelo menos até a década de 1980, continuou sendo realizada em São Paulo, quase que integralmente, de forma manual, com forte exigência temporária de força de trabalho. Acrescente-se que os ganhos de produção por área, advindos do uso de adubos, agrotóxicos, sementes melhoradas etc., aumentaram ainda mais a exigência de trabalhadores no período de colheita.

Em suma, a forma como se deu a mecanização, coadjuvada pelo uso de herbicidas, e o aumento da produtividade da terra associada às tecnologias químico-biológicas, fizeram com que se acentuasse a sazonalidade anual no uso de força de trabalho em importantes lavouras paulistas. Sazonalidade que, muitas vezes, passava a ser característica dos estabelecimentos agropecuários ou mesmo de regiões agrícolas, na medida em que, tendessem a se especializar nessas lavouras.

Tivesse a mecanização se estendido, desde o início, por todo o ciclo das principais lavouras em São Paulo, o processo poderia ter se caracterizado, predominantemente, pela substituição do grande número de colonos por pequeno número de trabalhadores permanentes com maior qualificação profissional, especialmente para o manejo de máquinas agrícolas. Estes, de fato, passaram a constituir parcela, menos expres- 
siva, diga-se de passagem, da ocupação agropecuária do Estado, se juntando aos trabalhadores sem qualificação profissional, contratados, temporariamente, nos momentos de maior exigência de força de trabalho.

Assim, no que se refere às empresas agrícolas, pode-se afirmar com segurança que a quase totalidade da força de trabalho não qualificada já foi excluída do emprego permanente, sendo substituída por força mecânica (ou química, como é o caso dos herbicidas), ou empregada apenas temporariamente nos 'picos' do processo produtivo. (BRANT, 1975, p. $81)$.

Em termos quantitativos, o número de pessoas ocupadas sofre influência do tipo de uso da área agrícola. Nesse sentido, tanto Brant (1975) como Graziano da Silva (1981) comentam que a diminuição da área de café após a crise de 1929/30 (fato subsidiado por políticas públicas de erradicação dos cafezais na década 1930, o que voltou a ocorrer no início dos anos 1960) e sua substituição por culturas temporárias e por pastagens contribuíram para a diminuição da ocupação na agricultura paulista. Saint (1980) atribui, talvez de maneira excessiva, influência significativa da alteração da composição da área agrícola não só no número de pessoas ocupadas, mas também na relação de emprego:

Esse processo de substituição ocorreu durante um período de 40 anos, entre 1930 e 1970 . À medida que as plantações de café, com sua força de trabalho composta de colonos que produziam também para subsistência, eram substituídas pela criação de gado e as lavouras de algodão (atividades menos intensivas em mão-de-obra), os residentes eram expulsos para as cidades próximas. Afastados da atividade produtiva, contribuíam para a crescente população marginal nas áreas urbanas. (SAINT, 1980, p. 506).

Continuando-se a discutir o uso da terra, pode- -se supor que, mais recentemente, o avanço da lavoura canavieira após 1975, ano de criação do Programa Nacional do Álcool (Proálcool), que se deu em grande parte sobre áreas de pastagens, tenha aumentado a necessidade de ocupação na agricultura paulista. Pelo menos nas regiões canavieiras e enquanto a mecanização não avançasse com celeridade em todas as etapas do plantio e no corte de cana-de-açúcar.

Nesse sentido, baseado em coeficientes técnicos de ocupação do IEA, estudo de Baccarin (1985) para a antiga Divisão Regional Agrícola (DIRA) de Ribeirão Preto, composta por oitenta municípios paulistas e com área de 3,6 milhões de hectares, mostra que, entre 1975 e 1980, a alteração mais significativa no uso da área local foi a diminuição de aproximadamente a 210 mil hectares de pastagens e o concomitante aumento de quase 200 mil hectares de cana-de-açúcar. Junto com outras mudanças no uso da área agrícola, isso resultou em crescimento de $16,5 \%$ no emprego agrícola regional no período, em quase $60 \%$ atribuíveis à expansão canavieira.

\section{A instabilidade DE tRabalho do VOlante}

Tomando por base a discussão anterior sobre a formação do trabalho volante na agricultura paulista, esta seção procura discutir algumas de suas condições de trabalho no início dos anos 1980, em especial aquelas associadas à instabilidade de sua ocupação. De pronto, deve-se problematizar a relação entre essa instabilidade e a sazonalidade de ocupação em determinada lavoura, que tende sempre a ocorrer, dada a diferença entre o tempo de trabalho e tempo de produção na agricultura. Nem por isso, tal fato, necessariamente e em qualquer circunstância, desembocaria no predomínio de emprego temporário e instável.

Já se viu que, sob o colonato, a sazonalidade da lavoura cafeeira, quase que integralmente ${ }^{12}$, era ${ }^{12}$ Graziano da Silva (1981) fala sobre a presença de trabalhado- 
67 BACCARIN. Retomando o debate sobre o trabalho volante na agricultura paulista dos anos 1980 resolvida com os trabalhadores necessários nos meses da colheita sendo mantidos no interior do próprio estabelecimento agropecuário por todo ano, dedicando-se a outras atividades agropecuárias, quando diminuía a necessidade de braços para o café. Ou seja, embora existisse grande sazonalidade de ocupação no café, o emprego era permanente, devido, em grande parte, à diversidade produtiva que se mantinha no estabelecimento agropecuário.

De forma semelhante, pode-se considerar que, em algumas sociedades camponesas, a produção artesanal permitia que a família se mantivesse ocupada todo o tempo, mesmo quando não houvesse atividades agropecuárias a serem executadas; isso até o momento em que a grande indústria não colocasse em cheque essa produção artesanal. Mas a literatura aponta também vários exemplos de camponeses, especialmente os detentores de menores áreas, que precisavam trabalhar periodicamente em atividades agrícolas, ou não, fora dos seus estabelecimentos, para complementar seus rendimentos e garantir sua reprodução.

Pode-se afirmar que a sazonalidade de ocupação sempre esteve presente na agropecuária, com maior ou menor intensidade. Arranjos sociais diversos se constituíram para seu enfrentamento, em casos como dois dos acima citados sem que se comprometesse o caráter permanente do emprego, à medida que, o trabalhador executava diversas tarefas em diferentes atividades agrícolas ou artesanais em um mesmo estabelecimento.

Mas, também há exemplos históricos que mostram que, desde muito tempo, o proprietário rural gerenciava a sazonalidade de ocupação sem que se garantisse ao trabalhador o emprego permanente. Nesse sentido, Marx (1982, capítulo XXIII) relata a existência de grupos de trabalhadores na agricultura

res temporários na agricultura paulista já no final do século XIX. Martins (2010) informa que, não raramente, pequenos agricultores independentes se juntavam aos colonos para a realização da colheita cafeeira.

britânica (mais evidentes na Irlanda que na Inglaterra) na primeira metade do século XIX, chamados de "bandos ambulantes" que, morando nas cidades, se deslocavam a pé diariamente, quando havia disponibilidade de emprego, por três a quatro milhas para os serviços no setor rural, sendo caracterizada em sua vida a intermitência dos vínculos de emprego.

Também Max Weber descreve a existência de trabalhadores temporários sazonais na agricultura alemã no final do século XIX, para atender às necessidades de grandes propriedades. Para o autor:

[...] o problema mais importante que qualquer constituição do trabalho no campo tem que resolver, em especial nas grandes unidades agrícolas que utilizam, não a força de trabalho familiar do proprietário, mas exclusivamente a força de trabalho alheia, é a questão da distribuição desigual de trabalhadores requeridos em cada uma das estações do ano[...]. por isso, via de regra, a agricultura, especialmente a da grande propriedade, além do conjunto fixo de trabalhadores, permanentemente à disposição da propriedade e ocupados todo o ano, necessita periodicamente de força de trabalho adicional; e as peculiaridades típicas de qualquer constituição de trabalho estão fundamentadas nas formas de suprimento destes dois tipos de demanda da força de trabalho. (WEBER, 1981, p. 29).

Uma questão a ser especificada, já insinuada anteriormente, é a distinção entre a sazonalidade de ocupação de uma lavoura e a de um estabelecimento ou região agrícola. Pode-se supor que, à medida que a especialização produtiva de determinado estabelecimento avance, sua sazonalidade de ocupação se aproxime à da cultura em que se está especializando, raciocínio que pode ser estendido considerando-se a região em vez do estabelecimento. Sendo isso correto, é possível afirmar que a instabilidade de ocupação ou as diferenças de demanda de mão de-obra, ao longo do ano agrícola, poderia ser maior em estabeleci- 
mentos ou regiões com menos diversidade produtiva em comparação com aqueles (as) que apresentassem diferentes culturas com picos de necessidade de mão-de-obra alternados no tempo.

Para a região canavieira paulista, a expansão dessa lavoura tendeu a diminuir a área de outras lavouras, como o algodão, que tinha grande necessidade de mão-de-obra em momentos não coincidentes com a colheita de cana-de-açúcar. E, como também já comentado, a forma como se deu a mecanização canavieira, pelo menos até a década de 1980, contribuiu para o aumento de sua sazonalidade de ocupação, bem como para a contratação de grande número de trabalhadores temporários durante sua colheita. Até certo ponto, a ampliação da colheita de cana-de-açúcar, de um período de três a quatro para seis a sete meses, agiu no sentido contrário, de reduzir a sazonalidade, embora o grosso dessa atividade continuasse ocorrendo entre maio e julho.

No momento da colheita de cana, de pico de demanda de mão-de-obra, reforçado pela expressiva coincidência com as colheitas de café e laranja no Estado de São Paulo, o contingente de trabalhadores temporários era aumentado de duas maneiras. Pelo assalariamento temporário de pequenos agricultores independentes, como consideram Kageyama (1982) e Gonzales e Bastos (1982) e pela incorporação de maior número de mulheres e menores ("boias-frias esporádicos”, na denominação de Graziano da Silva, 1981) às turmas de volantes.

Nas décadas de 1980 e 1990, era comum constatar-se a presença dos chamados migrantes sazonais ou pendulares, vindos, em sua maioria, de estados da Região do Semiárido (Norte de Minas Gerais, com grande predominância, e estados do Nordeste) para São Paulo para "fazer" a safra de café e, especialmente, de cana-de-açúcar. Em suas regiões de origem, eram, no mais das vezes, agricultores familiares, dedicados a lavouras e criatórios de subsistência, com maior necessidade de mão-de-obra em período coin- cidente com a entressafra de cana e café na região de destino.

Estudo de Baccarin (1988) sobre migrantes do Vale do Jequitinhonha (MG) aponta que a renda aí obtida era muito baixa e o assalariamento na safra de cana, quando escasseavam os serviços naquela região, representava estratégia fundamental para a realização de pequenos investimentos produtivos agrícolas e a reprodução de suas famílias. Esses autores afirmam que a migração sazonal se repetia, para a mesmo migrante junto, muitas vezes, com o mesmo patrão, por diversos anos. Mas também acontecia de parcela desses migrantes ficar definitivamente na região de destino, tendendo esse fato, aparentemente, a aumentar.

Na região canavieira, esses migrantes se alojavam em pensões e "repúblicas" nas pequenas cidades canavieiras ou em casas antigas (ex-colônias, comumente) e barracões construídos especialmente para tal fim no interior das propriedades rurais. No mais das vezes, esses alojamentos eram marcados pelo improviso e por apresentarem precárias condições de moradia.

$\mathrm{Na}$ entressafra, mesmo com a volta dos migrantes sazonais para sua região de origem, os empregos disponíveis reduziam-se fortemente na região canavieira ${ }^{13}$, colocando dificuldades para que todos os volantes locais continuassem empregados, diminuindo fortemente o número de "boias-frias esporádicos".

Entende-se que essa flutuação ou instabilidade no nível de emprego não pode ser interpretada como se a contratação dos volantes fosse, a todo momento, eventual, sem nenhuma previsão ou rotina ao longo do tempo. Dada a composição do uso da terra e o nível tecnológico, o número de volantes contratados tendia a ser parecido nos mesmos meses de diversos

\footnotetext{
${ }^{13}$ Dados trabalhados por pesquisadores do Instituto de Economia Agrícola (SP) para 1984 mostram que a cana-de-açúcar na região de Ribeirão Preto (SP) demandava 14,4 dias-homem por hectare no período da safra e 5,7 dias-homem/ha na entressafra, ou seja, a necessidade de mão-de-obra na entressafra era de apenas $40 \%$ da necessidade da safra (MELLO et alii, 1984).
} 
anos em determinada região.

Por exemplo, na região com predomínio canavieiro de Ribeirão Preto (SP), patrões e trabalhadores tinham noção e se programavam, até certo ponto, para o período da colheita de cana, de maior exigência de mão-de-obra. Sabiam também que na entressafra canavieira, havia alguns momentos que demandavam número expressivo de pessoas, como no plantio de cana ou, ainda, nas atividades de ralear e colher o algodão, na colheita do amendoim, na catação do milho e em diversas capinas. Contudo, é bom que se diga que estas últimas atividades eram de duração mais curta (em relação aos seis a sete meses da colheita da cana), o plantio da cana acontecia apenas a cada quatro anos no mesmo local, além do que as áreas de algodão e milho estavam diminuindo frente ao avanço canavieiro $^{14}$. Não raramente, na entressafra de cana, vários volantes ficavam desempregados por algumas semanas ou meses e se sujeitavam a trabalhos eventuais, inclusive no setor urbano. Mas, insista-se, essa não era a realidade de todos e em todos os dias do ano.

Graziano da Silva (1982) denomina esse grupo de volantes, sujeitos a muita instabilidade de emprego, de "boias-frias temporários." ${ }^{15}$. Além deles e dos já citados "boias-frias esporádicos", haveria os "boias-frias permanentes", constituindo as "turmas firmes" e que permaneciam empregados de forma contínua, às vezes por vários anos, em um mesmo estabelecimento agropecuário ou em vários estabelecimentos agropecuários, mas sob o agenciamento de

${ }^{14}$ No caso do amendoim, isso não acontecia, posto que essa cultura era cultivada nos meses que se estendiam entre o último corte de um canavial e o plantio de novo canavial na mesma área, na reforma dessa lavoura. Essa "convivência" do amendoim, de ciclo produtivo curto, com a cana-de-açúcar se observa até o presente.

15 "[...] pode-se destacar ainda um terceiro grupo, intermediário em termos de período que trabalham no campo, os 'boias-frias temporários' que são também empregados principalmente por ocasião das safras. A característica fundamental desse grupo é a de alternarem empregos rurais e urbanos, personificando a unificação do mercado de trabalho de mão-de-obra não qualificada." (SILVA, 1982, p. 165). um mesmo empreiteiro ou turmeiro de mão-de-obra. Com base em outros estudos, esse autor estima que os "boias-frias permanentes" representavam entre 15\%, na região de Presidente Prudente (SP), e 50\%, em torno de Ribeirão Preto (SP) e Campinas (SP), do total de volantes.

Convém discorrer sobre o papel do empreiteiro ou turmeiro de mão-de-obra. Muitas vezes, ele recebia a denominação de "gato", fato associado a práticas lesivas aos trabalhadores, como adiantamento em dinheiro embutindo-se altos juros, realização de acordos com proprietários de pequenos estabelecimentos comerciais para fornecimento a prazo de gêneros alimentícios com preços avultados, distorções na medição do trabalho diário, em prejuízo de alguns e em benefício de outros, amigos e parentes, porventura existentes na turma, descontos indevidos nos salários dos volantes.

Contudo, sua ação era mais complexa, em alguns aspectos beneficiando os trabalhadores. Como a remuneração do turmeiro se constituía de uma porcentagem do salário do volante, interessava-lhe que este fosse o mais alto possível. Também tinha o papel de sondar as oportunidades de trabalho e fazer contato com os empregadores de determinada região, dessa forma facilitando o acesso dos volantes aos empregos aí disponíveis.

Para o patrão, cumpria as funções de arregimentação da mão-de-obra e de fiscalização de seu desempenho. Ao patrão e ao turmeiro interessava que o rendimento diário do volante, no caso do pagamento por tarefa, fosse o mais alto possível, embora houvesse diferenciação entre os dois quanto à exigência da qualidade do serviço, muito maior no caso do patrão.

A descrição acima diz respeito ao "turmeiro típico" (BACCARIN, 1984), pessoa física que arregimentava uma ou mais turmas de volantes, ofertando seus serviços para diversos estabelecimentos agropecuários ao longo do ano. Com menor importância, 
constatava-se também a existência de firmas de empreita de mão-de-obra, aos moldes das atuais empresas de terceirização, com estrutura jurídica para assumir diretamente os encargos trabalhistas dos volantes.

Quanto a essa questão, o uso do turmeiro, muitas vezes, era encarado pelo empregador como uma forma de não precisar arcar com os direitos trabalhistas, acabando isso por acontecer, especialmente em trabalhos de curta duração. Muitas vezes argumentava-se que se contratava o turmeiro e, se houvesse relação de emprego, era entre ele e o volante e não com o agricultor.

A jurisprudência da Justiça do Trabalho caminhou em sentido contrário, considerando o turmeiro um mero preposto e que a relação de emprego se estabelecia entre volante e agricultor, ficando o mesmo sujeito a multas e indenizações em caso do descumprimento da legislação trabalhista. Isso, sem dúvida, contribuiu para aumentar a formalidade de trabalho do volante, muitos passando a contar com carteira de trabalho assinada, particularmente quando a tarefa a ser executada durava alguns meses.

Talvez por esse motivo, a contratação direta dos volantes passou a predominar entre as agroindústrias canavieiras da região de Ribeirão Preto (SP), como destaca Baccarin (1984). Nesse caso, o turmeiro se restringia a arregimentar e transportar a turma de volantes, deixando de exercer a funcão de fiscalização Quadro 1 - Distribuição porcentual de 50 volantes de Jaboticabal (SP), de acordo com condições de trabalho diversas, 1983.

\begin{tabular}{|l|l|l|l|}
\hline \multicolumn{1}{|c|}{ Condição } & \multicolumn{3}{|c|}{ Especificação e Porcentagem } \\
\hline Tipo de Trabalho & $\begin{array}{l}\text { Corte Cana } \\
74 \%\end{array}$ & $\begin{array}{l}\text { Apanha Laranja - } \\
16 \%\end{array}$ & Outros - 8\% \\
\hline Período Emprego & $\begin{array}{l}\text { Permanente } \\
26 \%\end{array}$ & Temporário - 74\% \\
\hline Formalidade & $\begin{array}{l}\text { Carteira Assina- } \\
\text { da }-76 \%\end{array}$ & Não Assinada - 14\% & Indefinida - 10\% \\
\hline Tipo Contratação & Direta - 80\% & $\begin{array}{l}\text { Firma de } \\
\text { Empreita }-\end{array}$ & Empreiteiro - 12\% \\
& & \multicolumn{2}{l}{} \\
\hline
\end{tabular}

Fonte: Autor, 1985.

e, não raramente, passando a ser também empregado com carteira assinada pela usina ou destilaria.

No Quadro 1 são apresentadas algumas condições de trabalho levantadas através de entrevistas de 50 volantes da cidade de Jaboticabal (SP), próxima a Ribeirão Preto (SP) e com amplo predomínio canavieiro em sua área. As entrevistas ocorreram em agosto de 1983, em pleno andamento das safras de cana-de-açúcar e laranja.

Quase três quartos dos trabalhadores estavam empregados no corte de cana e foi entre eles que se verificou o período de emprego permanente, que era condição de $26 \%$ dos volantes entrevistados. É bom esclarecer que não se tratava de contrato por tempo indeterminado, mas alternância de contratos de safra e de entressafra, sendo concedidas, comumente, entre eles, férias não remuneradas de quinze dias, para não se caracterizar vínculo permanente (em termos jurídicos) de emprego. O trabalho temporário, predominante entre os volantes, era de duração próxima a seis meses na colheita de cana ou da laranja e contava também, na maior parte, com registro em carteira.

Aliás, a formalização do contrato de trabalho foi constatada em $76 \%$ dos casos. Também muito generalizada mostrava-se a contratação direta, em $80 \%$ das situações, com as carteiras de trabalho sendo assinadas por agroindústrias canavieiras, fornecedores de cana e indústrias de suco de laranja. A intermediação 
do empreiteiro era verificada para os trabalhadores dedicados ao arranquio de colonião e catação de cana (outros tipos de trabalho) e para dois apanhadores de laranja empregados em estabelecimento que comercializava o produto in natura. A contratação via firma de empreita foi observada em algumas usinas de açúcar e etanol.

Ao se reportarem às condições da entressafra anterior, 1982/83, os volantes revelaram condições de trabalho totalmente diversas. Tal fato foi comprovado pelo acompanhamento da trajetória de onze dos trabalhadores inicialmente contatados, com entrevistas bimestrais até agosto de 1984.

Aqueles que tinham emprego permanente, na entressafra de cana se dedicavam a serviços gerais e a capinas dessa cultura, principalmente. Algumas empresas chegavam a diminuir ou evitar o uso de herbicidas, mantendo os trabalhadores ocupados na entressafra e garantindo que eles estariam disponíveis na safra seguinte de cana.

Dos outros trabalhadores, com período de emprego temporário, obtiveram-se informações que $20 \%$ deles se ocupavam em atividades urbanas na entressafra de cana e laranja, com amplo predomínio da construção civil. Na agricultura, conseguiam se ocupar em atividades de curta duração (no algodão e no amendoim, em especial), normalmente não contavam com carteira de trabalho assinada, eram agenciados pelos empreiteiros de mão-de-obra e, muitas vezes, ficavam sujeitos ao desemprego.

Durante a safra, 94\% dos volantes disseram ganhar até três salários mínimos, estando $69 \%$ deles na faixa de dois a três salários mínimos. $\mathrm{Na}$ entressafra, o nível salarial caía ainda mais (BACCARIN, 1985).

Ao fim desta seção, é preciso se reportar a mais duas condições de trabalho dos volantes no início dos anos 1980, relativas ao transporte e à forma de pagamento. $\mathrm{O}$ transporte diário entre a cidade $\mathrm{e}$ o local de trabalho agrícola era feito em carrocerias de caminhões, com os volantes (mal) acomodados em bancos de madeira e com as ferramentas de trabalho, como o podão de cortar cana, a seu lado. Os acidentes com os caminhões de turma, registrados com certa frequência, tinham caráter bastante trágico, com muitos feridos, às vezes pelo próprio podão, e mortos. Além disso, embora já à disposição do patrão, o tempo gasto no transporte, na ida e na volta do trabalho, não era computado nos salários dos volantes.

Quanto ao pagamento, no mais das vezes, era feito com base na produção diária do trabalhador, por exemplo, a quantidade de laranja, medida em caixa, apanhada ou de cana cortada no dia. Neste caso, como já relatado, havia uma disputa constante entre patrões e trabalhadores quanto à forma de se medir sua produção diária. Os trabalhadores conseguiam saber e eram comunicados pelos fiscais da quantidade de metro de cana que haviam cortado em determinado dia. Mas recebiam por tonelada de cana cortada, com a conversão da distância em peso sendo realizada após a cana ser pesada na usina ou destilaria, sem seu acompanhamento. Disso, resultavam costumeiras reclamações de subestimativas na pesagem da cana e, portanto, nos salários dos volantes.

Ao mesmo tempo, o pagamento por produção estimulava o trabalhador a produzir o máximo possível para aumentar seu ganho, indo até o limite de sua força física. Em média, cortava-se em torno de cinco toneladas de cana por dia, mas alguns trabalhadores passavam de dez toneladas. Não raramente, aconteciam casos de câimbras, esgotamento físico e, mesmo, internação dos volantes.

\section{CONSIDERAÇÕES FinAIS}

Do anteriormente exposto, podem-se apontar, para aprofundamento posterior, algumas condições e 
características que sofreram mudanças entre 1985 e o

presente e que conformaram a situação atual do traba-

lhador volante no Estado de São Paulo.

De pronto, afirma-se que essas mudanças, pelo menos no período inicial, foram impactadas pelas greves e revoltas dos volantes ocorridas em 1984, citadas na introdução deste artigo. Os trabalhadores ganharam, ainda que temporariamente, maior poder de barganha, enquanto os empresários passaram a considerar, pelo menos em nível de discurso, a possibilidade de aumentar o nível de mecanização canavieira.

Uma questão é a evolução da área canavieira e os efeitos sobre outras culturas e o resultante em termos de quantidade e sazonalidade de ocupação na agricultura paulista.

Também se devem abordar mudanças administrativas e tecnológicas no ramo sucroalcooleiro com impactos na forma e na quantidade de trabalhadores contratados. Entre as mudanças tecnológicas, destaquem-se as que estão ocorrendo no plantio e colheita de cana-de-açúcar.

Especificando um desdobramento disso, citem-se seus impactos na sazonalidade e formalização dos contratos de trabalho canavieiro, bem como seus efeitos na presença de migrantes pendulares na região canavieira.

Algumas outras condições de trabalho e suas transformações deverão ser abordadas, como a forma de pagamento, produção diária do volante, nível salarial, transporte, presença de mulheres e menores nas turmas.

Alterações da legislação trabalhista especificamente canavieira e as novas orientações liberais no mercado de trabalho, de forma geral, são outros pontos que se pretende desenvolver em texto futuro.

\section{REFERÊNCIAS BIBLIOGRÁFICAS}

BRANT, Vinícius Caldeira. Do colono ao boia-fria: transformações na agricultura e constituição do mercado de trabalho na Alta Sorocabana de Assis. Estudo CEBRAP, São Paulo, 19: 37-91, 1977.

BRASIL. Lei ${ }^{\circ}$ 4.214, de 2 de março de 1963. Dispõe sobre o "Estatuto do Trabalhador Rural". Disponível em http://www3.dataprev.gov.br/sislex/paginas/42/1963/4214.htm. Acesso em: junho de 2015.

BRASIL. Lei $n^{\circ} 5.889$, de 8 de junho de 1973. Estatui normas reguladoras do trabalho rural. Disponível em http://www.planalto.gov.br/ccivil_03/leis/L5889. htm. Acesso em: 8 jun. $2015 \mathrm{a}$.

BRASIL. Lei $\mathrm{n}^{\circ} 11.718$, de 20 de junho de 2008 . Acrescenta artigo à Lei no 5.889 , de 8 de junho de 1973 , criando o contrato de trabalhador rural por pequeno prazo; estabelece normas transitórias sobre a aposentadoria do trabalhador rural; prorroga o prazo de contratação de financiamentos rurais de que trata o $\S 60$ do art. 1 o da Lei no 11.524 , de 24 de setembro de 2007; e altera as Leis nos 8.171, de 17 de janeiro de 1991, 7.102, de 20 de junho de 1993, 9.017, de 30 de março de 1995 , e 8.212 e 8.213 , ambas de 24 de julho de 1991. Disponível em http://www.planalto.gov.br/ ccivil_03/ato2007-2010/2008/lei/111718.htm. Acesso em: 8 jun. $2015 b$.

COSTA PINTO, L. A. Migrações internas no Brasil. Rio de Janeiro: Instituto de Economia da Fundação Mauá, 1952. mimeo.

DEPARTAMENTO DE ECONOMIA RURAL FCA/ UNESP. A mão-de-obra volante na agricultura. São Paulo: Polís/CNPq/UNESP, 1982.

D'INCAO, Maria Conceição. O boia-fria: acumulação e miséria. Petrópolis: Vozes. 1975.

GONÇALVES, José Sidnei; CASTANHO FILHO, Eduardo Pires. Obrigatoriedade da reserva legal e impactos na agropecuária paulista. Informações Econômicas, São Paulo, v. 36, n. 9, p. 71-84, 2006.

GONZALES, Élbio N.; BASTOS, Maria Inês. O trabalho volante na agricultura brasileira. In: Departamento de Economia Rural FCA/UNESP (Org.). $A$ mão-de-obra volante na agricultura. São Paulo: Polis/CNPq/UNESP, 1982. p.35-55. 
. De boias-frias a empregados rurais: as greves dos canavieiros paulistas de Guariba e Leme. Maceió: EDUFAL, 1997.

IANNI, Otávio. A classe operária vai ao campo. $\mathrm{Ca}$ derno CEBRAP 24. São Paulo: Brasiliense. 1976.

IBGE (Instituto Brasileiro de Geografia e Estatística). Cidades. Disponível em http://www.cidades.ibge.gov. br/painel/populacao.php?lang=\&codmun $=351860 \&-$ search $=$ sao-paulo|guariba|infogr $\% \mathrm{E} 1$ ficos:-evo$\underline{\mathrm{u} \% \mathrm{E} 7 \% \mathrm{E} 30-\text { populacional-e-pir\%E2mide-et\%E1ria. }}$ Acesso em: 18 maio 2015.

LINHARES, Maria Yeda; SILVA, Francisco Carlos Teixeira da. História da agricultura brasileira: combate e controvérsias. São Paulo: Brasiliense, 1981.

LOPES, Juarez Rubens Brandão. Desenvolvimento e mudança social: formação da sociedade urbano-industrial no Brasil. 2a ${ }^{\mathrm{a}}$ ed. São Paulo: Nacional, 1972.

KAGEYAMA, Ângela Antonia. O emprego temporário na agricultura brasileira: seus determinantes $\mathrm{e}$ evolução recente. Reforma Agrária. Campinas, v. 12, n. 5, p. 3-12, 1982.

MARTINS, José de Souza. O cativeiro da terra. $9^{\text {a }}$. ed. revista e ampliada. São Paulo: Contexto, 2010.

MARX, Karl. O Capital: crítica da Economia Política. São Paulo: DIFEL, Livro I, vol. 2, Cap. XXIII. 1982. p. 712-827.

MELLO, Nilda Tereza Cardoso et alii. Estimativa de custo operacional e coeficientes técnicos das principais explorações agropecuárias, Estado de São Paulo, safra 1984/85. Informações Econômicas, São Paulo, v. 12, n. 7, p. 21-71, 1984.

MILLIET, S. Roteiro do café. São Paulo: Bipa, 1946.

SAINT, William S. Mão-de-obra volante na agricultura brasileira: uma revisão bibliográfica., Pesquisa e Planejamento Econômico, Rio de Janeiro, 10 (2): 503-526.

SÃO PAULO. Instituto de Economia Agrícola (IEA). Informações Econômicas. São Paulo, v. 9, n. 7, p. 1-177, jul. 1979.

SILVA, José Graziano da. Progresso técnico e relações de trabalho na agricultura. São Paulo: HUCITEC, 1981.

. O "boia-fria": entre aspas e com os pingos nos is. In: Departamento de Economia Rural FCA/ UNESP (Org.) A mão-de-obra volante na agricultura. São Paulo: Polís/CNPq/UNESP, 1982. p. 137-177.

WEBER, Max. A situação dos trabalhadores rurais da Alemanha nas províncias de Além-Elba - 1892. In: SILVA, José Graziano da; STOLCKE, Verena (Orgs.) A questão agrária. São Paulo: Brasiliense, 1981. p. 13-57. 